\title{
Localised Ridge Augmentation with Autogenous Block Bone Graft for the Restoration of Maxillary Anterior Teeth
}

\author{
Harsh Chansoria ${ }^{1}$, Shivakshi Chansoria ${ }^{2}$, Deshraj Jain ${ }^{3}$ \\ ${ }^{I}$ Department of Prosthodontics, College of Dentistry/Devi AhilyaVishwavidyalaya, India. \\ ${ }^{2}$ Department of Oral Medicine, Diagnosis and radiology, Index Institute of Dental \\ Sciences Devi AhilyaVishwavidyalaya, India, Country Name \\ ${ }^{3}$ Department of Prosthodontics, College of Dentistry/Devi Ahilya Vishwavidyalaya, India.
}

\begin{abstract}
Resorption of alveolar ridge is a common sequel of tooth loss. It is even more if trauma occurs. In such cases it becomes a challenge for the dentist to restore esthetics and function. Therefore augmentation of alveolar ridge is an important aspect of dental implant therapy. Here is a case of step by step procedure of restoration of localized maxillary ridge deficiency successfully treated with symphyseal block bone graft.
\end{abstract}

Keywords: Bone graft, dental implant, esthetics, ridge augmentation, ridge defect,

\section{Introduction}

Restoration of lost tooth with dental implant without compromising the adjacent teeth has become most acceptable and widely used treatment plan these days. However for dental implant to be successful the jawbone must have enough bone to support it. Often the bone available is inadequate to perform the ideal, predictable treatment and build a proper foundation. As a consequence bone grafting has become a more frequent modality to achieve long term success and ideal esthetic results.

Various reconstruction techniques have been used (bone grafting, guided bone regeneration, orthognathic surgery or bone distraction) out of which autogenous bone grafts are considered as gold standard in the repair of bone defects. In the repair of localized alveolar defect, cortical bone graft from the mandible offer several benefits like [1]-

1. Convenient surgical access

2. Proximity of the donor and recipient, reduces the operative and anesthesia time

3. Minimal donor site discomfort

4. Decreased morbidity

5. Biological benefit

Over the years intraoral block type grafts have been used for residual bone augmentation. The block graft may be harvested from residual ridge, mandibular symphysis, body and ramus.

\section{Case Presentation}

Patient reported to our department, with a chief complaint of missing teeth in the upper front tooth region since last 5 yrs and wanted replacement for the same. The tooth 12 and 22 were lost following a traumatic injury 5 years back due to which patient presented with Sibert's Class I type of ridge. The patient was systemically healthy with good periodontal condition and oral hygiene of the remaining teeth. Scaling and polishing was performed 2 weeks prior to the implant placement surgery. Thickness of the soft tissue was assessed at different points around the planned recipient site using transgingival probing.

These types of ridges can present with buccal dehiscence defect during placement of implants, which can be augmented using autogenous bone graft $[2,3]$. The use of block autografts is indicated primarily when an increase in ridge volume is desired, especially as part of implant site development. Grafting with autogenous bone has been documented to be highly effective in reconstructing jaw anatomy, restoring esthetics and providing biomechanical support for the placement of dental implants.

A two - stage implant surgical procedure was planned with simultaneous use of bone grafting to cover the dehiscence in the labial aspect that may appear during the placement procedure. After evaluating the clinical and radiographic findings, an implant of $13 \mathrm{~mm}$ length and $3.75 \mathrm{~mm}$ diameter was considered ideal for the site taking into consideration the fact that the tooth-implant distance should be greater than or equal to $3 \mathrm{~mm}$ at the site and the distance between two implants should be around $1.5 \mathrm{~mm}$. The case presented in this article is clinically important because it demonstrate the efficacy of using a block bone graft in generating effective new bone fill for dental implant placement. 


\section{Investigations}

Radiographs were obtained to evaluate the bone where implants were planned to be placed. Radiographic evaluation showed thin buccal bone, although there was adequate bone height $(17 \mathrm{~mm})$ and mesiodistal width for the placement of the implant. The remaining bone was of good quality with sufficient bone density (D3) (Fig.1).

\section{Surgical Procedures:}

\section{Treatment}

After anesthetizing the surgical site using infiltration anesthesia, a full thickness (mucoperiosteal flap) was elevated following a horizontal incision on the palatal aspect of the alveolar ridge. The flap was reflected to the labial surface to expose the underlying bone (Fig. $2 \& 3$ ). The point of insertion on the bone was marked with the help of a round bur this was followed by drilling with subsequent drills till the site is prepared for the final size of the root form external hex implant (Hi tech life care) to be placed (Fig. 4). The implant was removed from the sterile packaging and placed in the prepared cavity (Fig.5).

\section{Bone Grafting:}

The donor site was first anesthetized by giving local anesthesia in front and below each mental foramen and at the base of mental protuberance. Vestibular Incision is given in the mucosa below the lower front teeth and extends distally till the region of canine (Fig. 6) and a full thickness mucoperiosteal flap was raised. After the symphysis was exposed the osteotomy is performed to achieve the determined dimension of bone from donor site (Fig. $7 \&$ 8). A block of bone was harvested (Fig. $9 \& 10$ ) and placed into the area where implants were exposed (Fig. 11). The donor site is closed after the block graft is fixated and the soft tissue is sutured (Fig. 12).

\section{Second Surgical Stage:}

After a healing period of 5 month a radiograph was taken to evaluate the status of placed implants which was found to be satisfactory (Fig. 13).A tissue punch was then used to uncover the implant and healing abutment was placed on to it. After two weeks, the implant analogue was united with the impression coping (Fig.14) and implant level impression was made on which crown were fabricated accordingly (Fig. 15). The abutment screws were threaded into position in the implant after removing the gingival former (Fig. 16) and the final restoration was cemented to the abutment (Fig. 17). The patient was kept on regular maintenance appointments during which the esthetics \& functioning of the restoration was found satisfactory. A one-year postoperative radiograph showed maintenance of adequate bone level and density around the implant (Fig. 18).

\section{Conclusion}

A wide range of surgical procedures were identified, but only those which improve the long term implant survival were given the priority. Autogenous block bone graft is an effective technique for bone dehiscence at the time of implant placement.

\section{Discussion}

Dehiscence defect can occur during the implant placement thereby exposing some of the implant threads. Lekholmet al, 1996 [4] said that the exposed screws can be left uncovered without any adverse reaction. However in our case the magnitude of bone defect was bit large so it needs to be augmented for implant stabilization and success. There are a variety of different techniques and materials for bone grafting, out of which autogenous bone grafts are considered as gold standard in the repair of bone defects. Simultaneous placement of bone grafts and implants shortens the treatment time without increasing complications or reducing the success rate (Boronat et al, 2010). [5] Regardless of the donor site for autogenous block grafts, 4 to 6 months of healing is necessarybefore dental implants can be placedinto the region. This staged technique using autogenous bone blocks is themost frequently used grafting techniquebecause of its general clinicalsuccess and predictability in implantsite development [6]

\section{References}

[1]. Carl E. Misch; Contemporary implant dentistry; $3^{\text {rd }}$ edition, 889-894

[2]. Hammerel CH, Jung RE; Ridge augmentation procedures In Clinical periodontology and Implant Dentistry (vo1.2).J Lindhe,NP Lang, T Kaming, Eds; 5 thEdn: Blackwell publication Munksgaard,2008:pp:1090-1092.

[3]. KahnbergK.E:Graftingprocedure.In:Bone grafting Techniques for maxillary Implant. K-E kahnberg,LRasmusson and G Zellin, Eds; $1^{\text {st }}$ Edn:Blackwell Publishing Co; Munksgaard,2005;pp:14-23.

[4]. Lekholm U Sennerby L, Roos J, Becker W: Soft tissue and marginal bone conditions at osseointegrated implants that have exposed threads- A 5 year retrospective study. International Journal of Oral and Maxillofacial Implants, 1996;11(5):599-604.

[5]. Boronat A, Carrillo C, Penarrocha M, Pennarocha M:Dental implants placed simultaneously with bone grafts in horizontal defects: a clinical retrospective study with 37 patients. International Journal of Oral and Maxillofacial Implants, $2010 ; 25(1): 189-196$.

[6]. Jovanovic SA, SpiekermannH,Richter EJ. Bone regeneration around titanium dental implants in dehisced defect sites: A clinical study. Int J Oral Maxillofac Implants. 1992;7:233-245. 


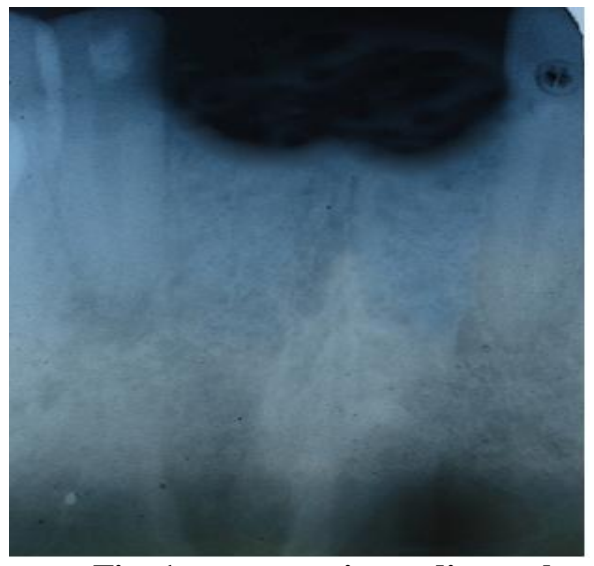

Fig. 1 pre-operative radiograph

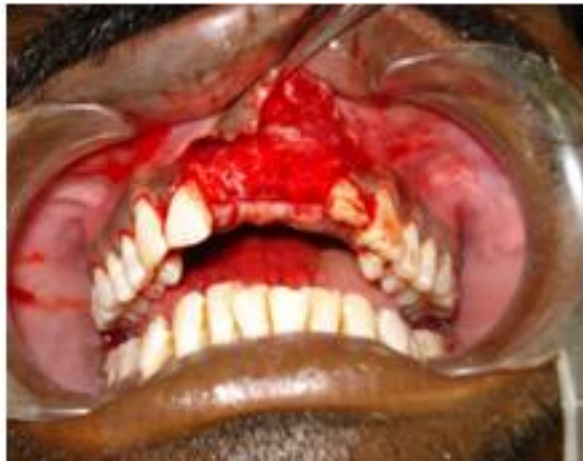

Fig. 3 mucoperiosteal flap

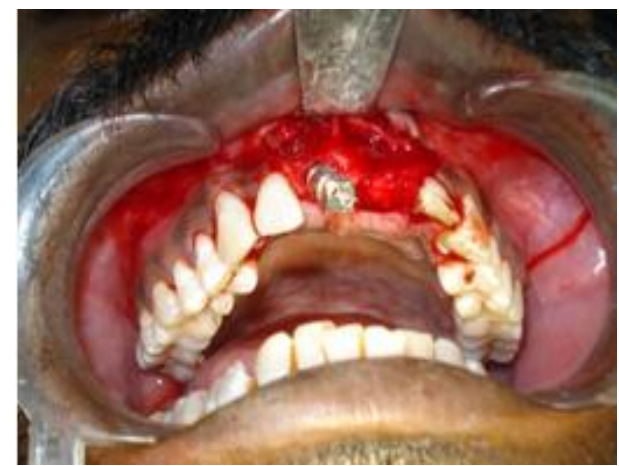

Fig. 5 implant in place

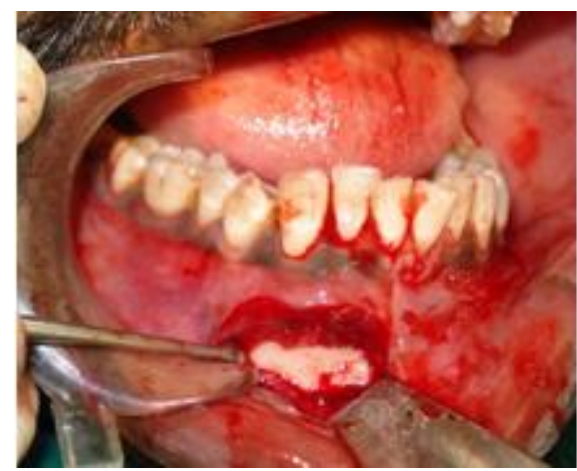

Fig. 7 donor site

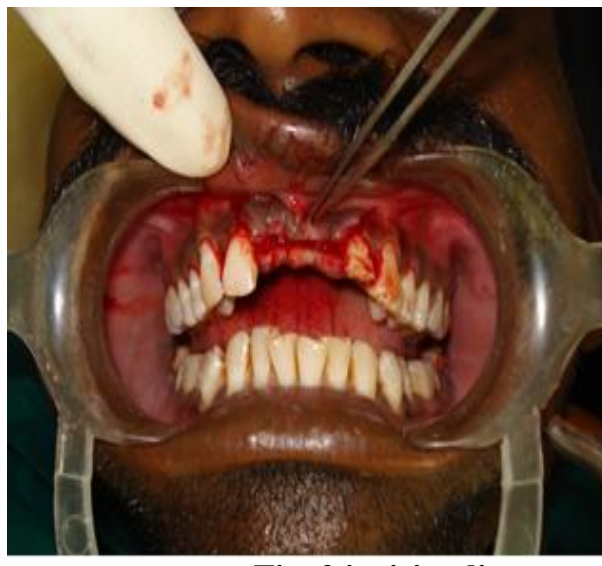

Fig. 2 incision line

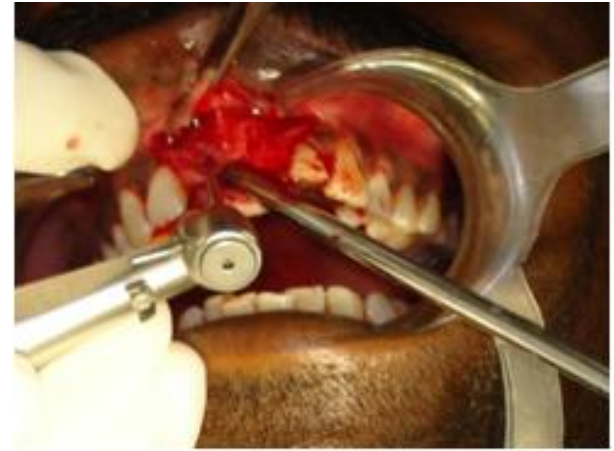

Fig. 4 drilling

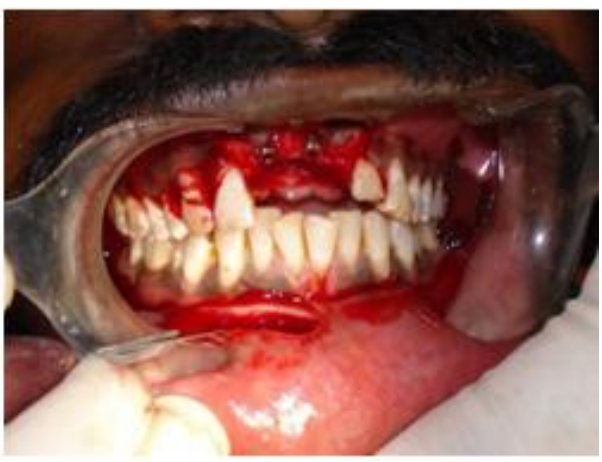

Fig. 6 vestibular incision

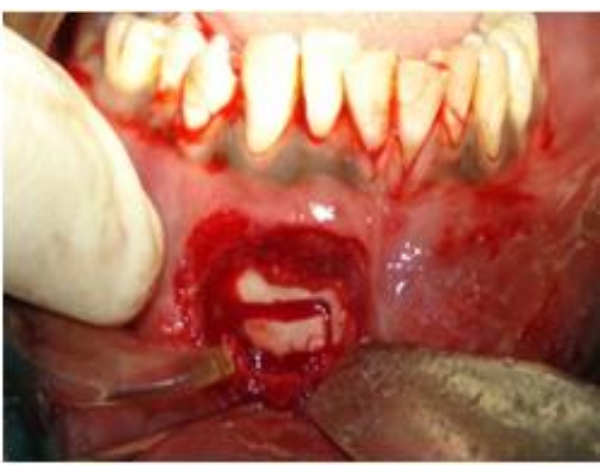

Fig. 8 osteotomy at donor site 


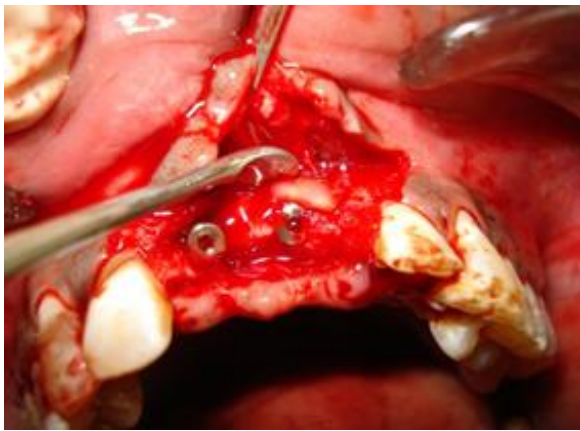

Fig. 9 Harvested block bone

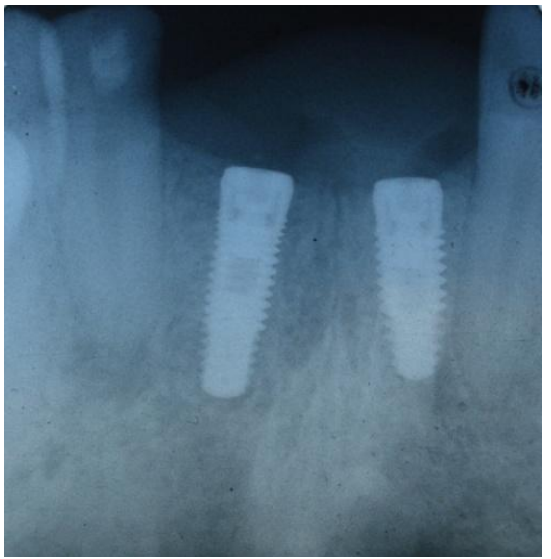

Fig. 10 operative site sutured with Interrupted sutures

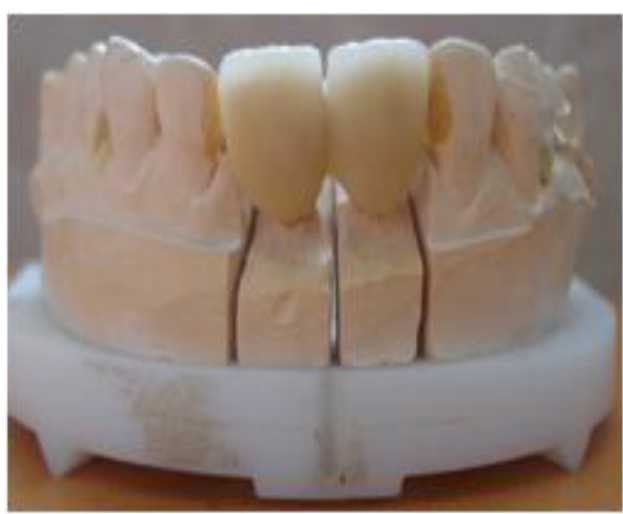

Fig. 13 fabricated Prosthesis

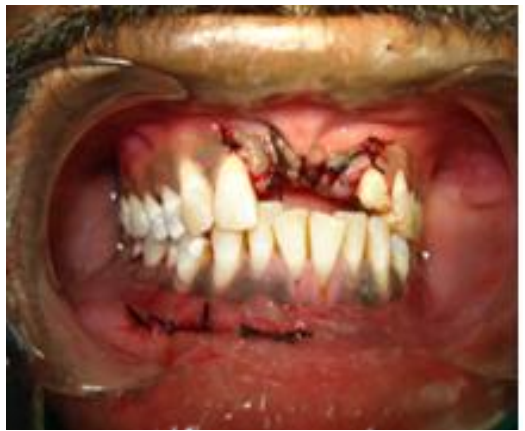

Fig. 10 operative site sutured with interrupted sutures

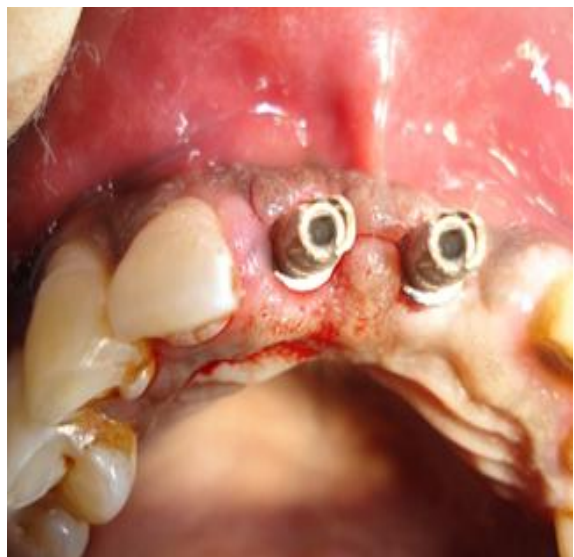

Fig. 11 Post operative radiograph after 5 months

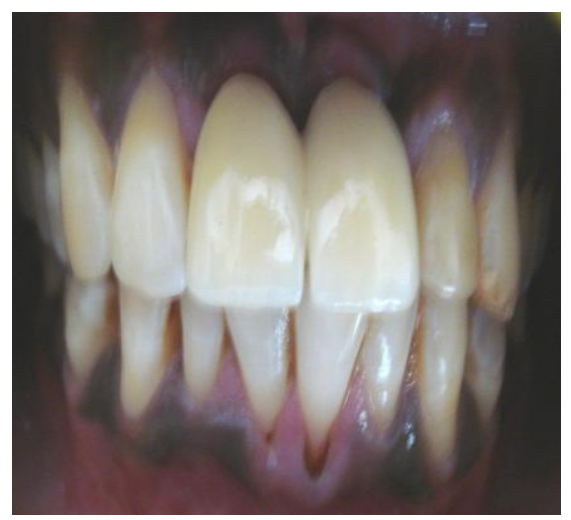

Fig. 14 final prosthesis in patient mouth

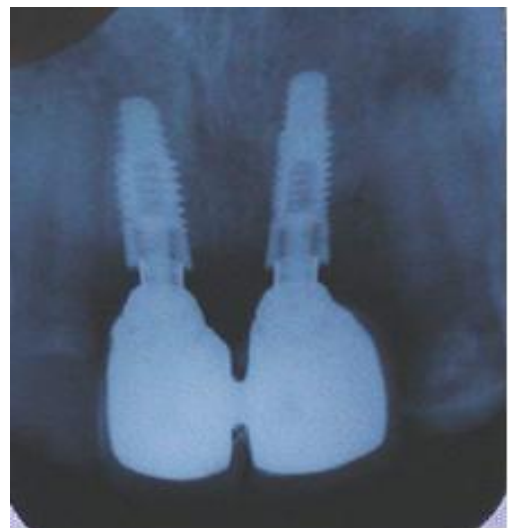

Fig. 15 post-operative photograph after one year 